\title{
Hypocenter distribution and heterogeneous seismic velocity structure in and around the focal area of the 2008 Iwate-Miyagi Nairiku Earthquake, NE Japan-Possible seismological evidence for a fluid driven compressional inversion earthquake
}

\author{
Tomomi Okada ${ }^{1}$, Norihito Umino ${ }^{1}$, Akira Hasegawa ${ }^{1}$, and Group for the aftershock observations of \\ the Iwate-Miyagi Nairiku Earthquake in $2008^{2}$ \\ ${ }^{1}$ Research Center for Prediction of Earthquakes and Volcanic Eruptions, Graduate School of Science, \\ Tohoku University, 6-6 Aramaki-Aza-Aoba, Aoba-ku, Sendai 980-8578, Japan \\ ${ }^{2}$ Refer to an author list at the appendix.
}

(Received April 7, 2009; Revised March 26, 2012; Accepted March 30, 2012; Online published September 18, 2012)

\begin{abstract}
We have done seismic tomography in and around the focal area of the 2008 Iwate-Miyagi Nairiku Earthquake (M 7.2) occurred on June 14, 2008 in NE Japan. We used data from temporary aftershock observation network deployed just after the occurrence of the present earthquake. Based on the distribution of aftershocks, the fault plane of the mainshock is inferred to dip to the west. Small immediate foreshocks and preceding seismic activity in 1999-2000 on the fault plane in the vicinity of the hypocenter of the mainshock of this earthquake were observed. Lower-seismic-velocity hanging wall can be imaged in the central and the northern part of the focal area. This possibly suggests the present earthquake is a compressional inversion earthquake. The low-velocity zone in the lower crust extends upward to the upper crust, branches into three portions and reaches each active volcano. This low-velocity region can be seen just beneath the mainshock hypocenter and the whole focal area, suggesting that crustal uid possibly promote the occurrence of the 2008 earthquake.
\end{abstract}

Key words: Seismic velocity structure, aftershock, foreshock, inversion tectonics, crustal uid.

\section{Introduction}

A large shallow earthquake (named the 2008 IwateMiyagi Nairiku Earthquake) with a Japan Meteorological Agency (JMA) magnitude of 7.2 occurred in the central part of NE Japan on June 14, 2008. Focal area of the present earthquake is located in the Tohoku backbone range strain concentration zone (Miura et al., 2002) along the volcanic front. The focal mechanism or moment tensor shows reverse-type focal mechanism (cf. United States Geological Survey (USGS) MOMENT TENSOR (http://neic.usgs.gov/neis/eq_depot/2008/ eq_080613_tfdp/neic_tfdp_fmt.html), National Institute for Earth Science and Disaster Prevention (NIED) MOMENT TENSOR (http://www.fnet.bosai.go.jp/event/tdmt.php?ID= 20080613234200\&all=\&v=\&LANG=en\&?LANG=en)).

The compressional inversion tectonics is dominated in NE Japan at present (e.g. Sato et al., 2002; Sibson, 2009). In Miocene when Japan-sea was opened, many normal faults are formed under the extensional stress regime. At present these old normal faults act as reverse fault under the present compressional stress regime. In the case of the 2003 northern Miyagi earthquake ( $M$ 6.4), which is about $40 \mathrm{~km}$ south from the present earthquake, this compressional inversion

Copyright (C) The Society of Geomagnetism and Earth, Planetary and Space Sciences (SGEPSS); The Seismological Society of Japan; The Volcanological Society of Japan; The Geodetic Society of Japan; The Japanese Society for Planetary Sciences; TERRAPUB.

doi:10.5047/eps.2012.03.005 earthquake shows that high-dip angle of fault plane or aftershock alignment and also shows lower velocity hanging wall (Okada et al., 2007a). The plausible cause of the reactivation of such an unfavorably or badly oriented fault is over-pressurized uid (Sibson, 1990). In the previous paper (Okada et al., 2010), we have found a distinct low-velocity zone in the lower crust just beneath the focal area. These low-velocity zones might correspond to the area with overpressurized uid, which is originated from the upwelling ow in the mantle wedge.

Just after the occurrence of this earthquake, Japanese universities (Hokkaido, Hirosaki, Tohoku, Tokyo, Nagoya, Kyoto, Kochi, Kyusyu, Kagoshima) and NIED (National Research Institute for Earth Science and Disaster Prevention) deployed a dense aftershock observation network in and around the focal area (Fig. 1). Total number of temporal stations is 128 . Using data from this aftershock observation and other temporary and routinely operated stations, we estimate hypocenter distribution and seismic velocity structure of the crust in and around the whole focal area of the present earthquake in more detail.

\section{Data and Method}

We determined three-dimensional seismic velocity structure and relocated hypocenters simultaneously using the double-difference tomography method (Zhang and Thurber, 2003).

We adopted two-step procedure. First, we have done 


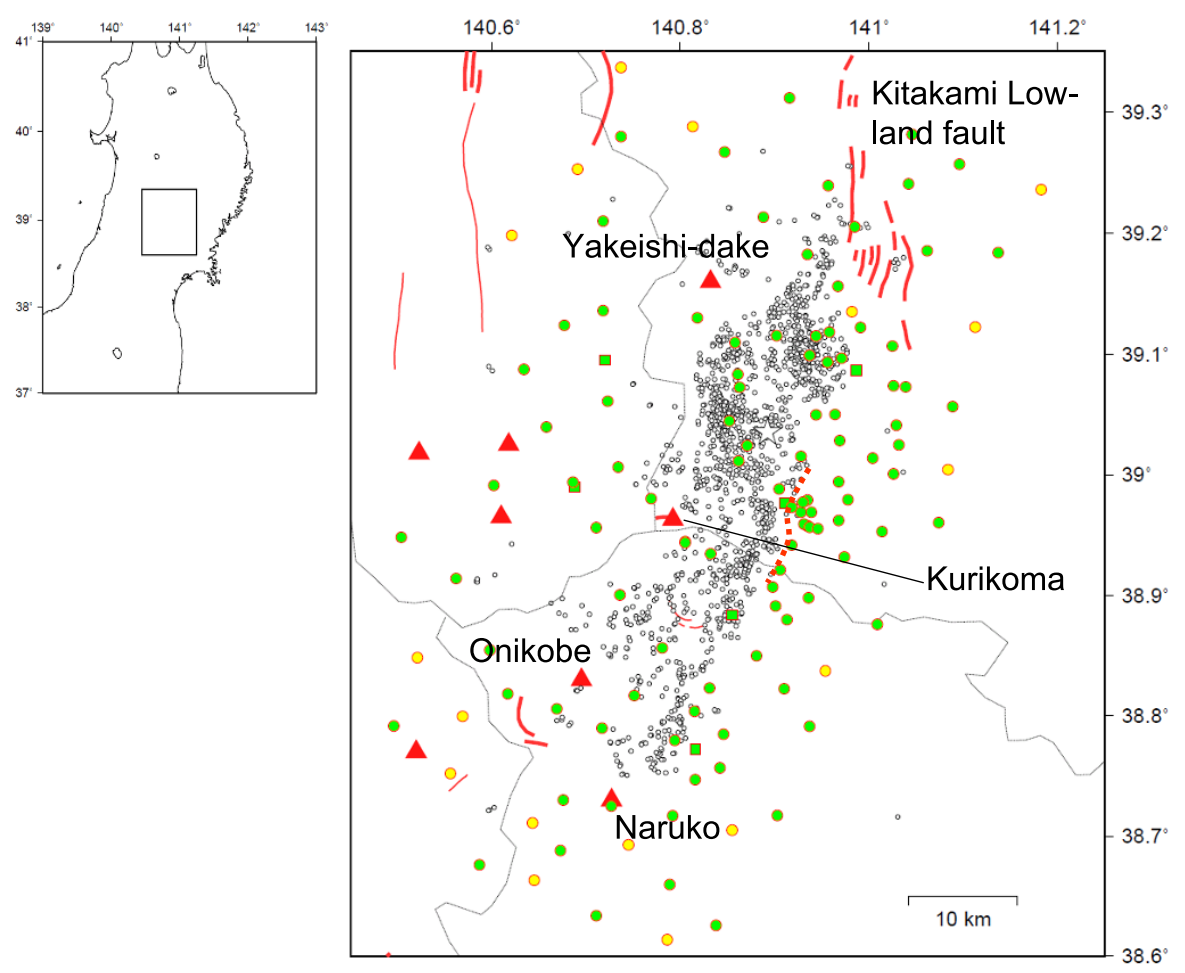

Fig. 1. Distribution of stations deployed by the Group for the aftershock observations of Iwate-Miyagi Nairiku Earthquake in 2008. Green and yellow circles denote the off-line stations deployed in the period from 2008/6 to 2008/10 and from 2008/6 to 2008/8, respectively. Green squares denote the on-line stations deployed in the period from 2008/6 to 2008/10. White open circles denote the aftershocks within 1 week after the mainshock from the Tohoku University automated catalog. Triangles denote volcanoes. Bold lines denote the surface traces of the active faults. Red broken line denotes the approximate location of Mochikorobashi-Hosokura Tectonic Zone (MHTZ). Thin lines indicate the prefecture boarders.

regional-scale tomography to obtain rough and deep image in this area (see Okada et al., 2010 for details). We used the shallow seismicity and intermediate depth seismicity in the subducting slab as a data set. Initial velocity structure is Hasegawa et al. (1978). Total number of earthquake is about 26000 . We used a grid net with intervals of 0.05 degrees in north-south and east-west directions and at depths of $0,6,12,18,24,36,48,60,80,100,120$, and $140 \mathrm{~km}$. The resolution is estimated to be about $10 \mathrm{~km}$ to $20 \mathrm{~km}$ in whole crust.

Second, we relocate aftershocks and recalculate threedimensional seismic velocity structure by using dense aftershock observation data. Initial velocity model is the previous one. We used a grid net with an interval of about $3 \mathrm{~km}$ in horizontal directions and at depths of $0,1,3,6,9,12,15$, 18, 24, 30, 36, 48, 60, 80, 100, 120, and $140 \mathrm{~km}$ (Fig. 2). We used 5571 earthquakes (two foreshocks, mainshock, aftershocks and other earthquakes occurred around the focal area) in the period from June 14 to Sep. 30 from the JMA unified catalog. Number of $P$-wave arrival time and $S$-wave arrival time are 562857 and 452030, respectively. In addition, differential times obtained with a cross-spectral analysis were used. We estimate the differential time from cross spectrum, which is calculated for the vertical component of motion in the $1.28 \mathrm{~s}$ interval including the initial $P$-wave or $S$-wave motions in a frequency range of 3-12 Hz. A total of $303839 P$-wave and $26340 S$-wave differential times obtained within $5 \mathrm{~km}$ of the hypocenter with coherence of 0.95 or higher were used. Total travel time residual is from 0.14 s to 0.06 s. Figure 3 shows the checkerboard resolu-

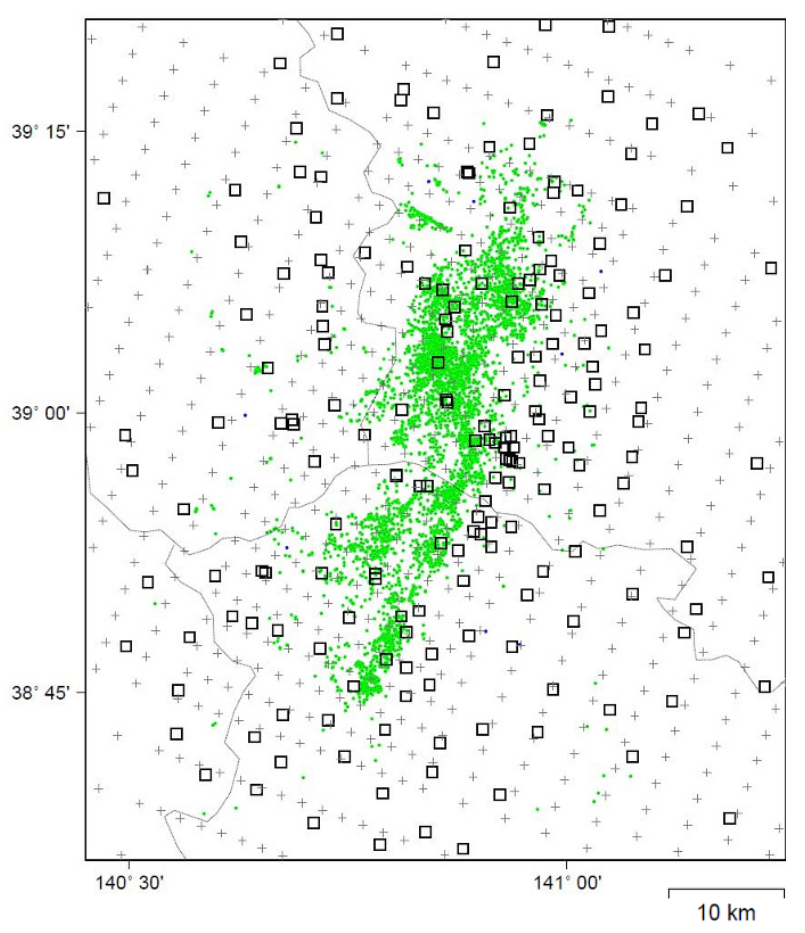

Fig. 2. Data set in this study. Open squares, small crosses, and green dots denote the stations, grids, and epicenters of aftershocks, respectively. We set the grids at depths of $0,1,3,6,9,12,15,18,24,36,48,60 \mathrm{~km}$. 
(a)
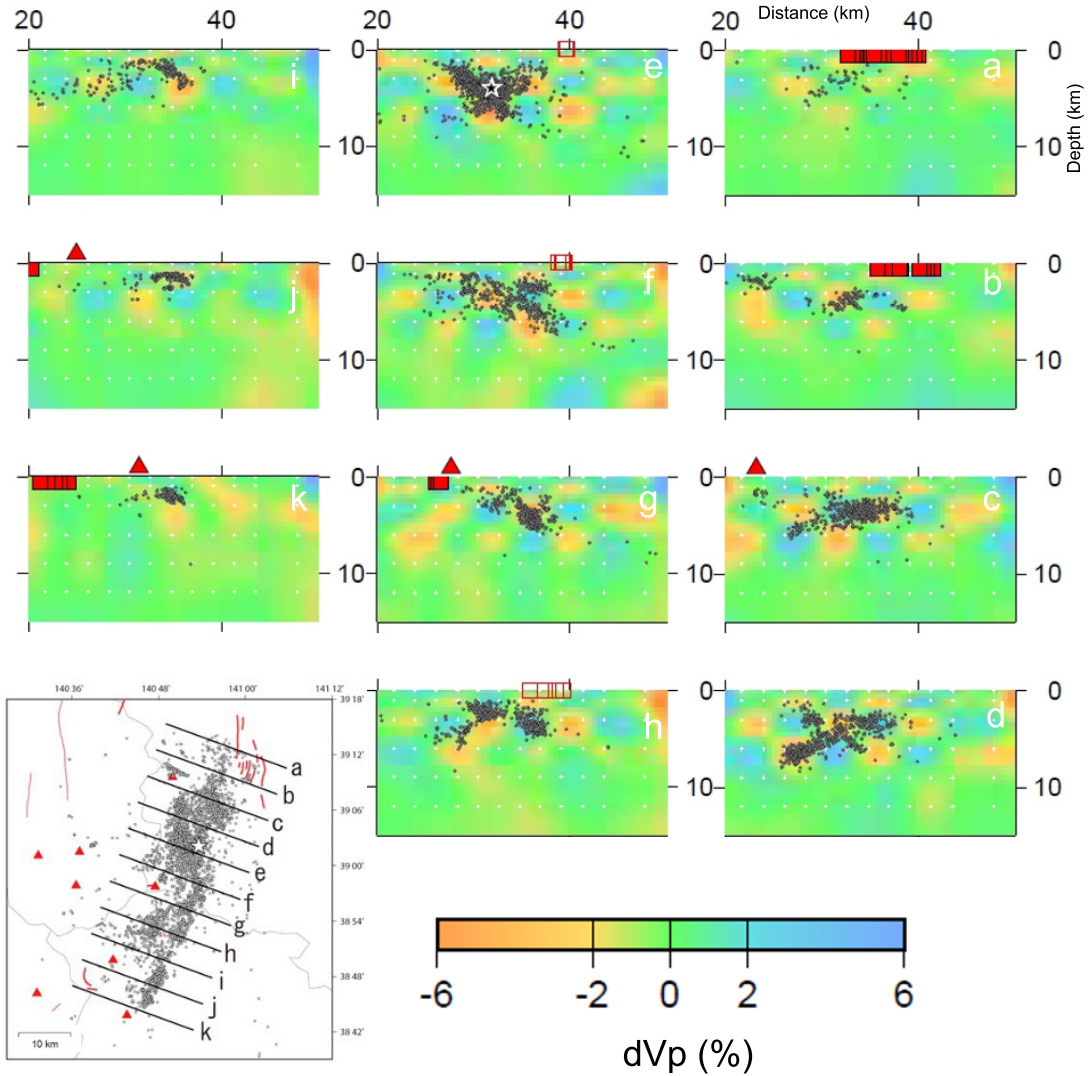

(b)
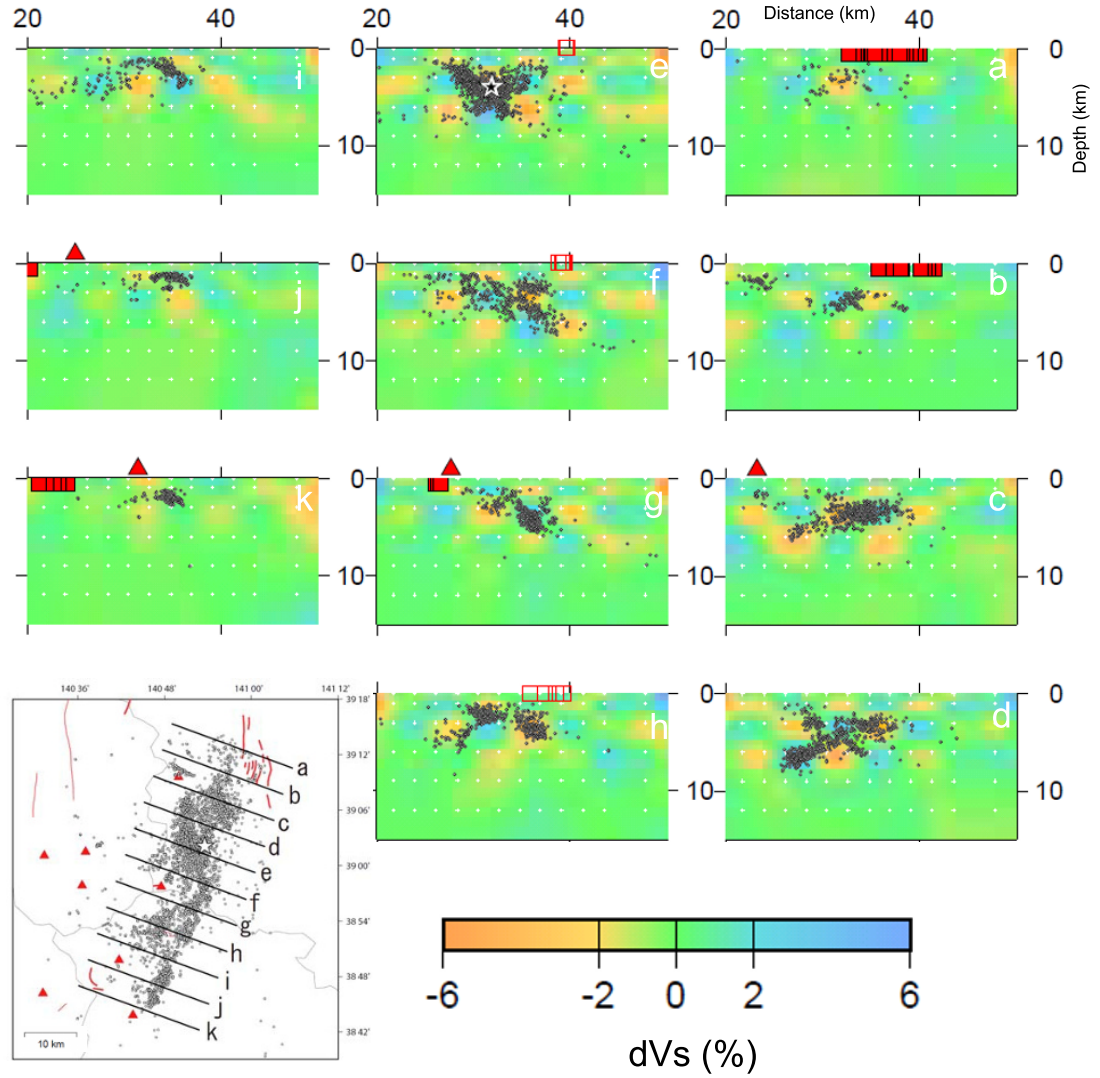

Fig. 3. Result of the checkerboard resolution test for (a) $d V_{p}$ (perturbation in the $P$ wave velocity) and (b) $d V_{s}$ (perturbation in the $S$ wave velocity)). Eleven across fault cross sections are shown. Locations of cross sections are shown in the insert map with the label of a to k. Red solid and open squares denote the location of the active fault and the surface deformation, respectively. Triangles denote volcanoes. Star denotes the mainshock hypocenter. White cross denote the grid used in the tomography. 

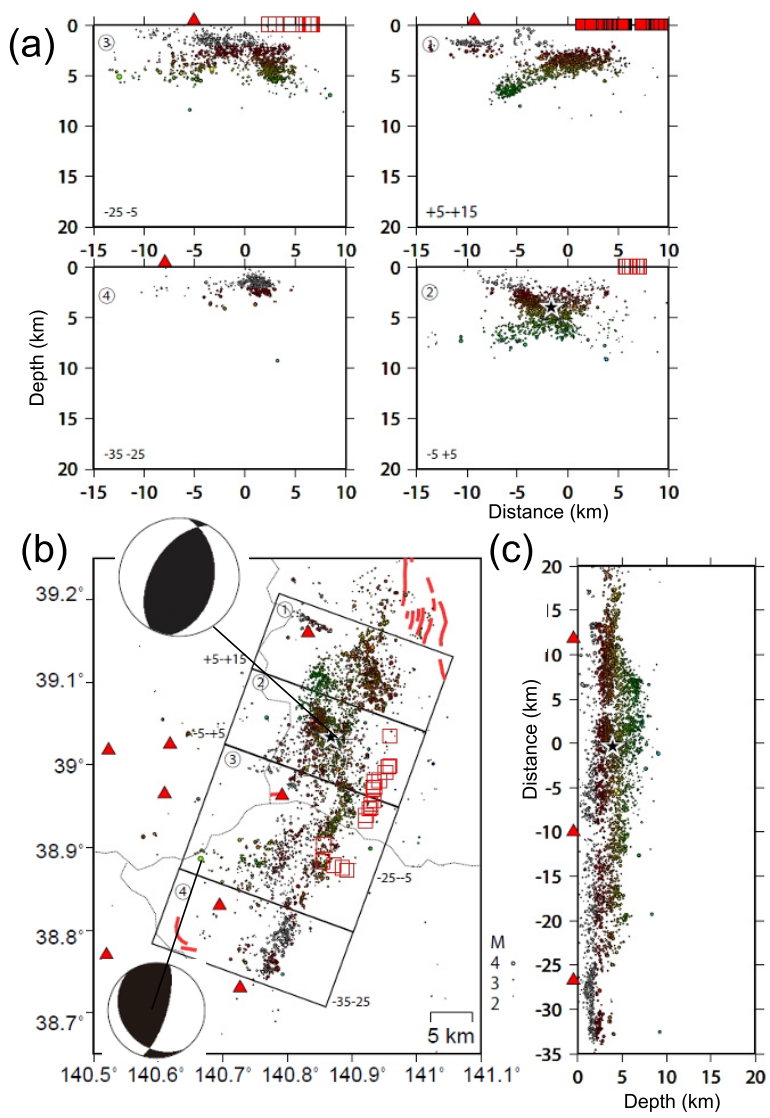

Fig. 4. Aftershocks, foreshocks and mainshock distribution. Small circles, black stars and white star denotes aftershocks, foreshocks and mainshock, respectively. Color of small circle means the depth of hypocenter. Triangles denote volcanoes. Open red squares denote the locations of the surface deformations. (a) The across fault cross section. Solid red squares denote the surface of the active faults. (b) Epicenter distribution. Bold lines denote the surface traces of the active faults. Large squares denote the locations of vertical cross sections in (a). Moment tensor solutions by F-net, NIED for the main shock and the largest aftershock are also shown. (c) The along-fault (NNE-SSW) cross section.

tion test in the second step. The amplitude of the velocity perturbation is \pm 5 percents, and the size of the pattern is 2 grids in horizontal and 1 grid in vertical. We can see that the resolution become better and is estimated to be about 6 $\mathrm{km}$ in horizontal and $3 \mathrm{~km}$ in vertical in upper crust where the aftershocks are distributed both for $P$-wave and $S$-wave in this case.

\section{Results}

\subsection{Distribution of hypocenters of mainshock, fore- shocks and aftershocks using temporary observa- tion data}

The hypocenter distribution thus obtained is shown in Fig. 4. The aftershock region extends in the NNE-SSW direction for approximately $45 \mathrm{~km}$ along strike with a width of $15 \mathrm{~km}$. The area in which the largest slip occurred during the mainshock (e.g. Ohta et al., 2008), as will be discussed in more detail later, extends for 15-20 km SSW from the hypocenter of the mainshock, at a shallow depth. The aftershocks occurred in an area that was significantly elongated in the N-S direction compared to the major slip area of the mainshock.
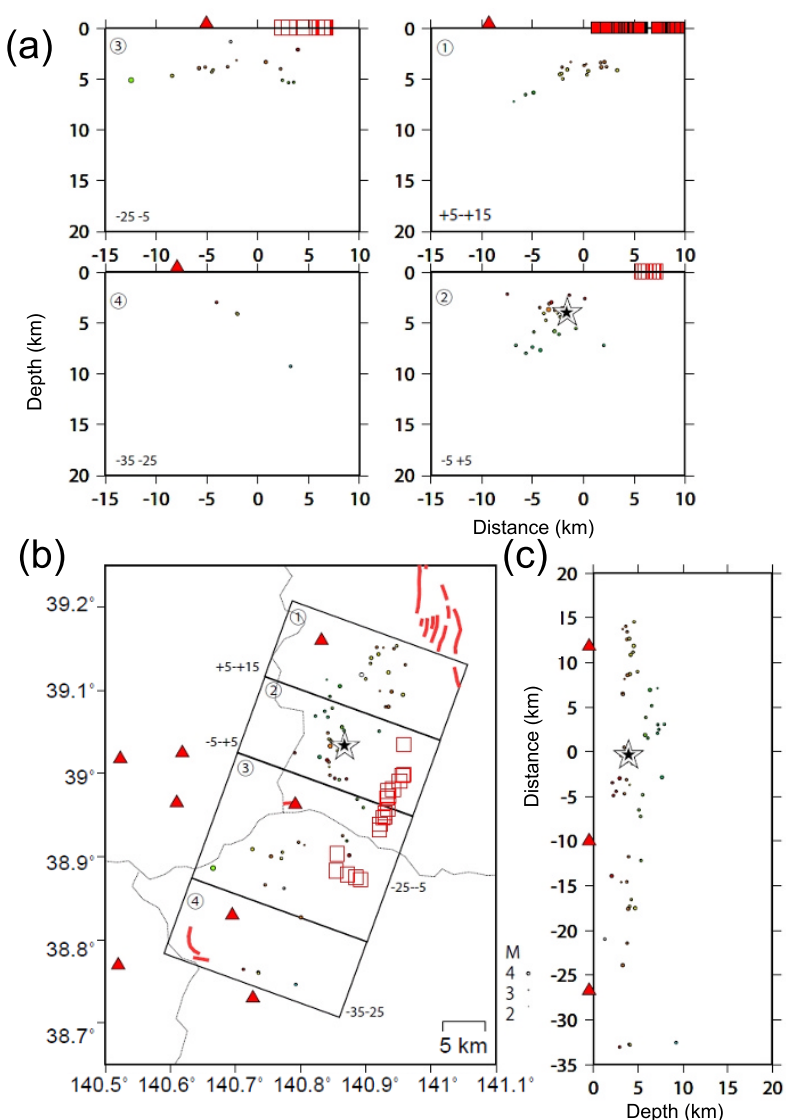

Fig. 5. Aftershocks for 1 hour, foreshocks and mainshock distribution Details except moment tensor solutions are the same as Fig. 4.
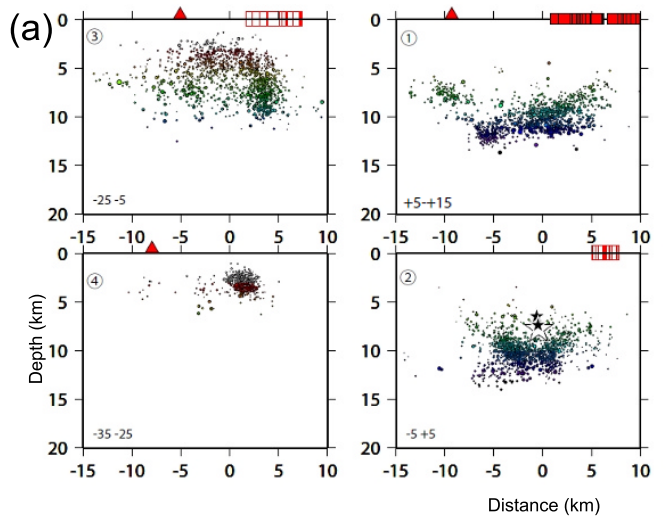

[JMA]
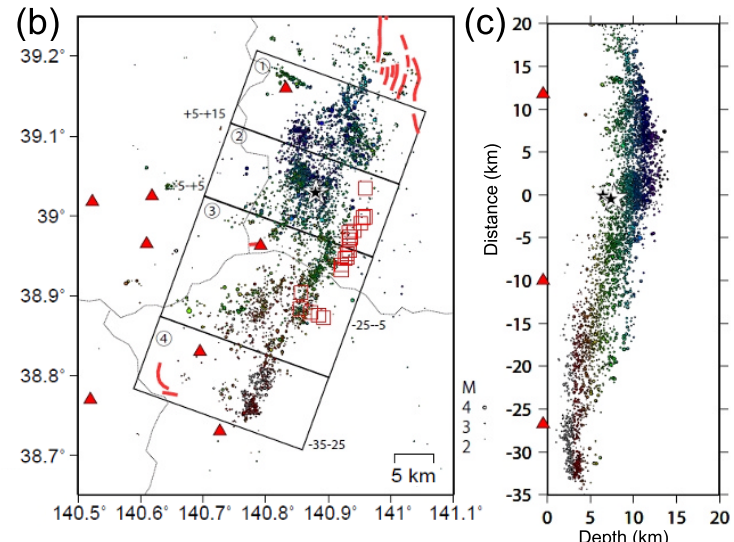

Fig. 6. Aftershocks, foreshocks and mainshock distribution from the JMA unified catalog. Details except moment tensor solutions are the same as Fig. 4. 
In the vicinity of the mainshock (Fig. 4(a) 2), the distribution of aftershocks forms a plane that dips to the west at approximately $40^{\circ}$, similar to the angle of the fault plane of the neighboring earthquakes, the 2003 North Miyagi Earthquake (M 6.4) (Okada et al., 2003; Umino et al., 2003) and 1962 North Miyagi Earthquake (M 6.2) (Hasegawa et al., 2005). This westward dipping aftershock alignment is thought to be along the major fault plane of the mainshock, as suggested by the GPS observation (cf. Ohta et al., 2008). Note that "eastward" dipping aftershock alignment can be seen in the vicinity of the main shock (Fig. 4(a) 2).

The aftershock distribution is very complex but in the early stage it is relatively simple. In Fig. 5, we show aftershocks only for one hour just after the mainshock. Near the mainshock, the westward dipping aftershock alignment is seems to be dominated in the earlier stage. This westward dipping alignment is a dip angle of 45 degrees. This angle is consistent with the westward dipping fault plane of the focal mechanism.

On June 14, immediately prior to the 2008 earthquake, an $M 0.6$ foreshock occurred at 8:01 and an $M 1.6$ foreshock occurred at 8:11 (see Fig. 4). Both are very close to the mainshock.

Ground deformation would caused by this earthquake has been con rmed (e.g. Toda et al., 2008), and location of the deformation belt is closely located with the Mochikorobashi-Hosokura Tectonic Zone (MHTZ). The shallow extension of the aftershock distribution is in approximate agreement with the position of ground deformation (Fig. 4). In the north of the source region, the shallower extension of the aftershock distribution meets roughly near the surface trace of the Kitakami Lowland fault (cf. Sato $e t$ al., 2008).

We can see spatial variation of lower limit of aftershock distribution along the focal area shown in Fig. 4(c). In the central part of the aftershock region, in the vicinity of the mainshock, the lower limit of aftershocks is relatively deep $(\sim 10 \mathrm{~km})$, while that the northernmost and southernmost parts tends to be shallower $(<5 \mathrm{~km})$ (Figs. 4(b) and (c)). The spatial distribution of the lower limit of aftershocks is expected from the microearthquakes prior to the 2008 earthquake, and represents the regional variation in the seismogenic layer in this region (Hasegawa et al., 2000). The lower limit of the seismogenic layer corresponds to the boundary between brittle and ductile deformation, and is determined by temperature. The northern edge (Mt. Yakeishi-dake) and southern edge (the Onikobe and Naruko volcanoes) of this region would be at higher temperature than the central part, resulting in shallower lower limit of seismicity in these regions.

Figure 6 shows the mainshock and aftershock distribution from the JMA Uni ed catalog (Japan Meteorological Agency, 2008). No clear aftershock alignment can be seen and the focal depths of the aftershocks in central and northern parts of the aftershock area are determined to be at larger depth, comparing with the aftershock distribution obtained in this study. This is due to the JMA catalog does not use the dense aftershock observation data and does not take the three dimensional seismic velocity structure into account.

\section{Preceding Seismic Activity}

It has also been con rmed that preceding seismic activity occurred in the vicinity of the mainshock of the 2008 earthquake (see Fig. 7), including an $M 4.5$ earthquake on April 19, 1999, and an M 4.9 earthquake on February 11, 2000. We relocated these earthquakes and their aftershock by the same procedure. Aftershock alignments of these two earthquakes follow on a shallow extension of the westward dipping plane of aftershocks following the 2008 Iwate-Miyagi Earthquake. It is therefore inferred that these preceding events occurred on the same fault plane as the 2008 earthquake. The aftershock and source regions of the 1999 and 2000 earthquakes are within the aftershock region of the 2008 earthquake, although the aftershock activity related to the 2008 event was relatively weak in the aftershock areas of the 1999 and 2000. Such preceding earthquake activity near the mainshock hypocenter has been reported for the 2000 Western Tottori earthquake (M 7.3) (Shibutani et al., 2002). This suggests that slip occurred during the 1999 and 2000 earthquakes on the same fault plane of the 2008 latest earthquake, resulting in a release of strain and causing the relatively low aftershock activity following the 2008 earthquake.

\subsection{Comparison of the aftershock distribution with the seismic velocity structure}

Figure 8 shows the close up image near the fault for $P$-wave velocity $\left(V_{p}\right)$ distribution. Near the mainshock hypocenter (cross section e), lower seismic velocity hanging wall for the westward dipping aftershock alignment can be imaged and the westward dipping aftershock alignment seem to be almost parallel to the iso-velocity contour of $P$ wave velocity $\left(V_{p}\right)$.

This observations means that the fault plane of the present earthquake is possibly correspond to the velocity changing zone and hanging wall has lower velocity than the footwall. This is the same as the previous compressional earthquakes as the 2003 northern Miyagi earthquake and others recently occurred in NE Japan (e.g. Okada et al., 2005, 2007a).

We can also see the eastward-dipping aftershock alignment. Crustal deformation detected by InSAR suggests the possible eastward-dipping fault plane which seem to almost correspond to this eastward-dipping aftershock alignment (e.g. Takada et al., 2009). The hanging wall for these eastward-dipping alignments do not have a lower seismic velocity than the footwall (Figs. 8(g), (h) and (i)). This is the same as for the conjugate $M 6$ aftershock of the 2004 Mid Niigata (Chuetsu) earthquake (e.g. Okada et al., 2005). This might suggest eastward-dipping alignment may means relatively newly developed fault or the fault which is less developed in Miocene in comparison with the major westward-dipping fault plane.

Note that the some part of low-velocity body in the upper crust has low $V_{p} / V_{s}$ ( $S$-wave velocity; $\left.V_{s}\right)$ (Fig. 9). Matsubara et al. (2004) found a seismic low-velocity body with low $V_{p} / V_{s}$ in the upper crust beneath the northern part of the Kitakami Low-land fault. Okada et al. (2007a) also found a seismic low-velocity body with low $V_{p} / V_{s}$ around the fault in the upper crust of the 2003 northern Miyagi earthquake. The low velocities with low $V_{p} / V_{s}$ can be in- 


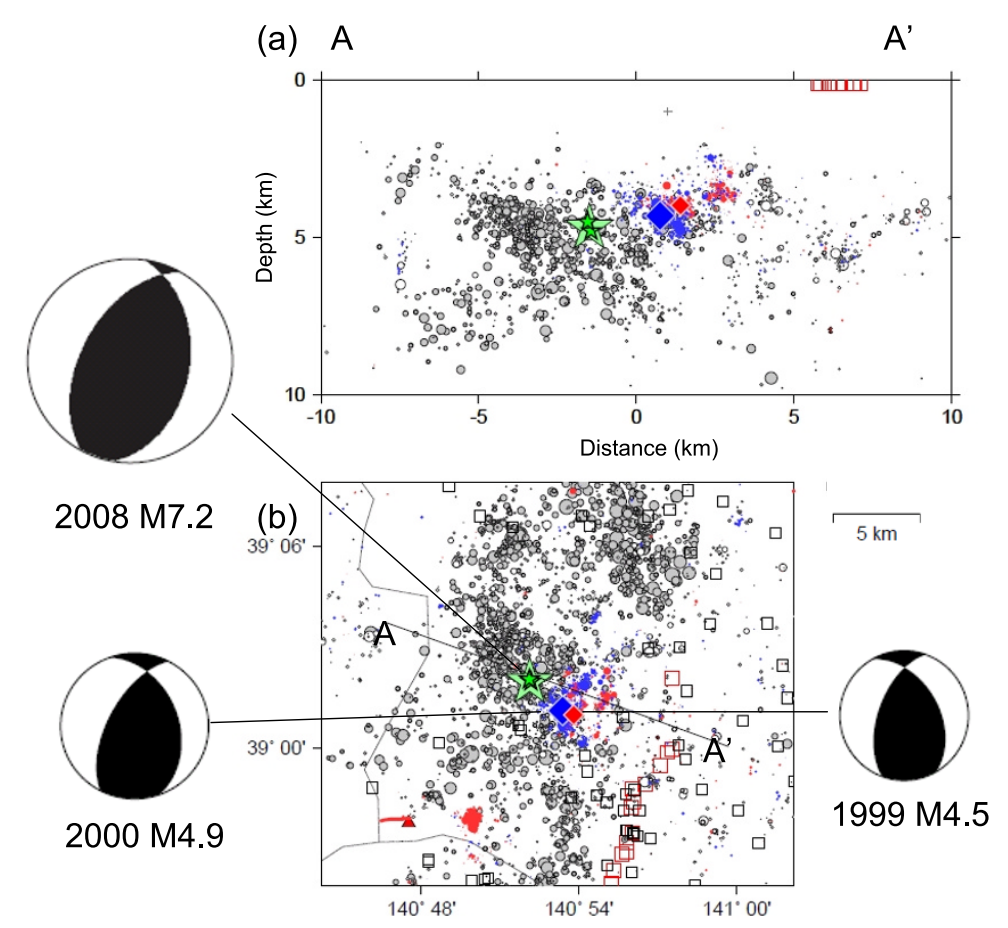

Fig. 7. Hypocenter distribution of the $2000 M 4.9$ and $1999 M 4.3$ earthquakes. The events in 2000 and 1999 are shown in blue and red, respectively. Mainshocks are shown by diamonds. The aftershocks, foreshocks and mainshock in 2008 are shown in gray circles, green small stars and green large star, respectively. Open red squares denote the locations of the surface deformations. (a) The across-fault cross section in a width of 5 km. (b) Epicenter map. Location of the cross section is shown by line. Focal mechanisms (NIED moment tensor solutions) of the $2000 M 4.9,1999 M 4.3$ and 2008 M 7.2 earthquakes are also shown. Black open squares denote the stations.
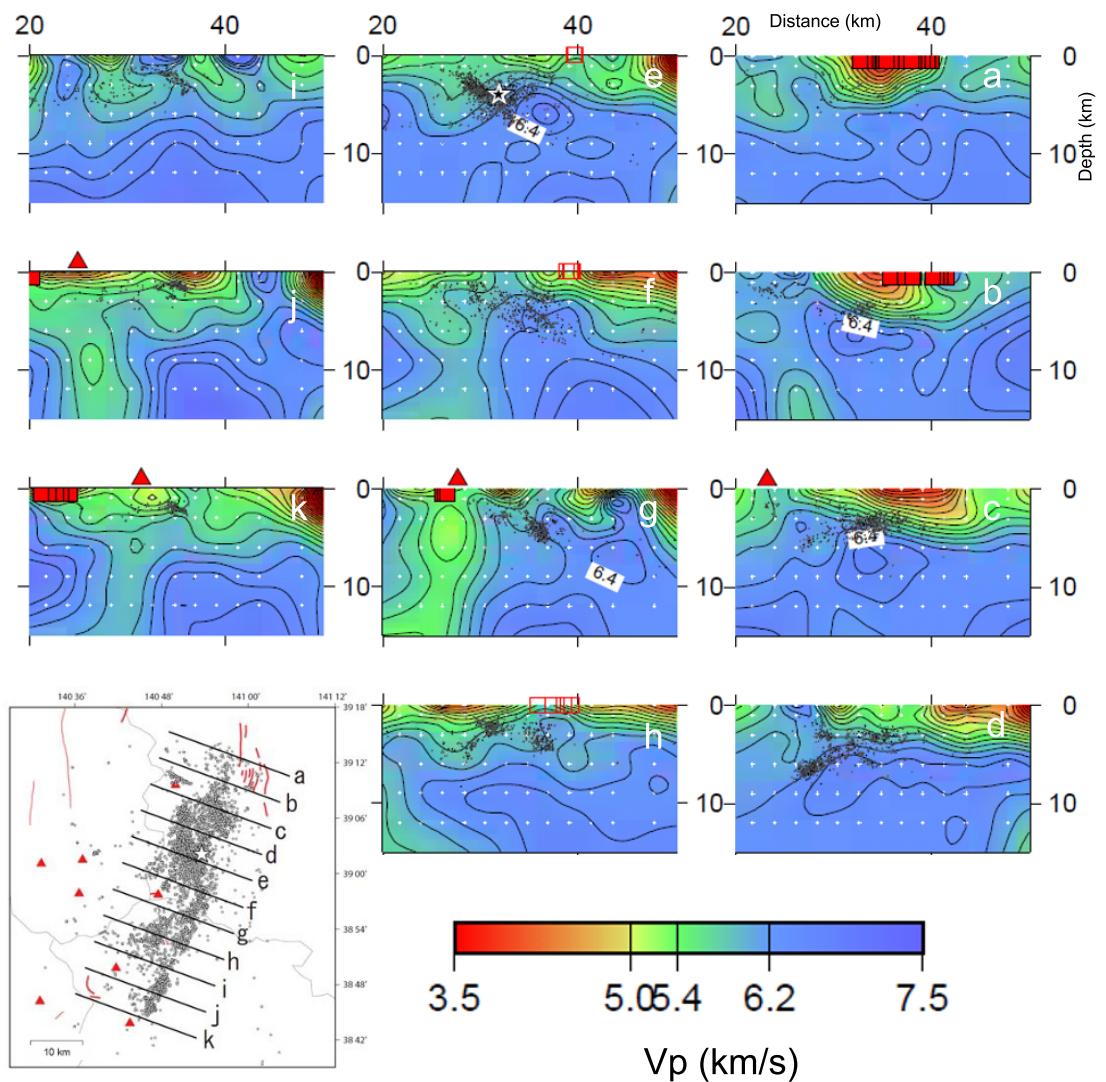

Fig. 8. $V_{p}$ distribution. Eleven across fault vertical cross sections are shown. Locations of cross sections are shown in the insert map with the label of a to k. Red solid and open squares denote the location of the active fault and the surface deformation, respectively. Triangles denote volcanoes. Contour interval is $0.2 \mathrm{~km} / \mathrm{s}$. White cross denote the grid used in the tomography. 

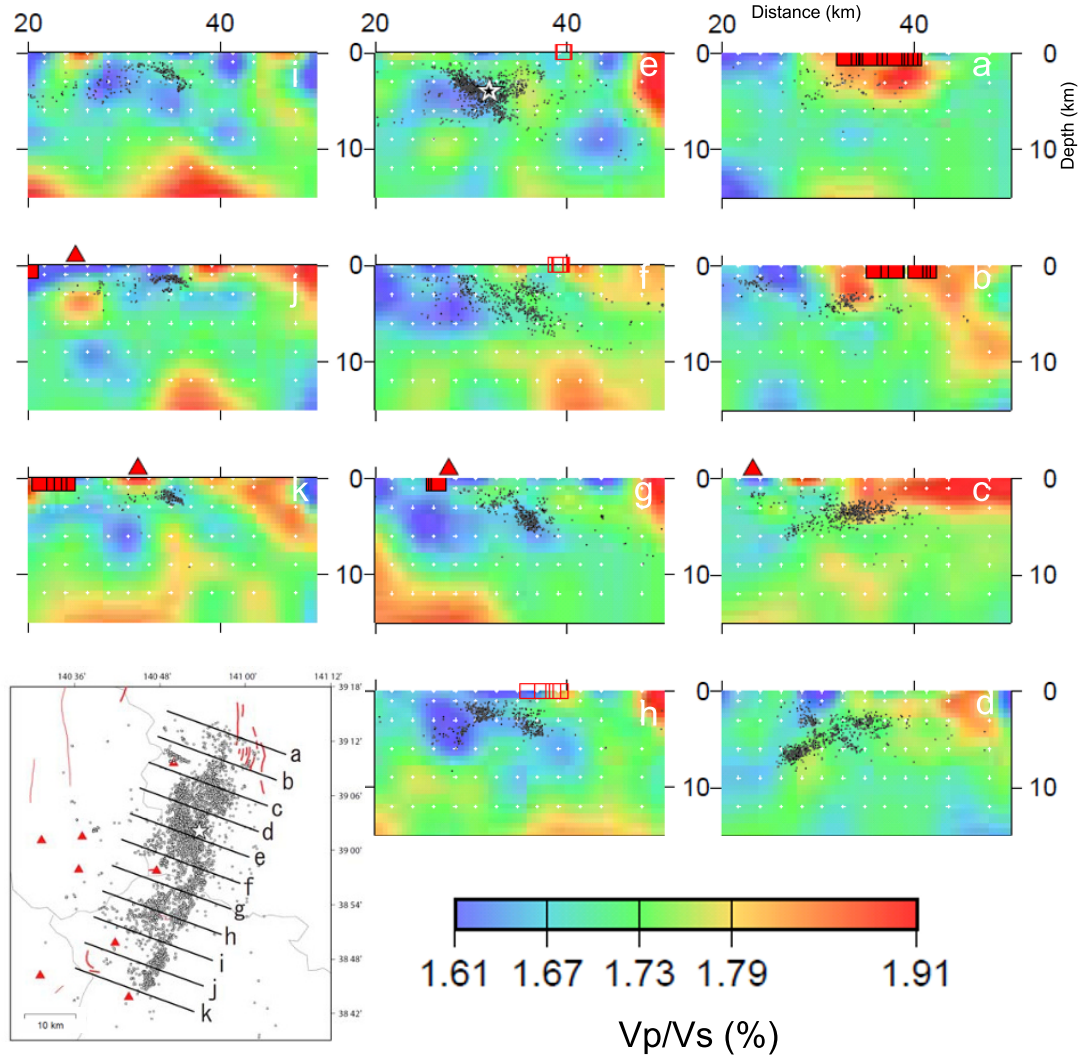

Fig. 9. $V_{p} / V_{s}$ distribution. Eleven across fault cross vertival sections are shown. Locations of cross sections are shown in the insert map with the label of a to k. Red solid and open squares denote the location of the active fault and the surface deformation, respectively. Triangles denote volcanoes. White cross denote the grid used in the tomography.

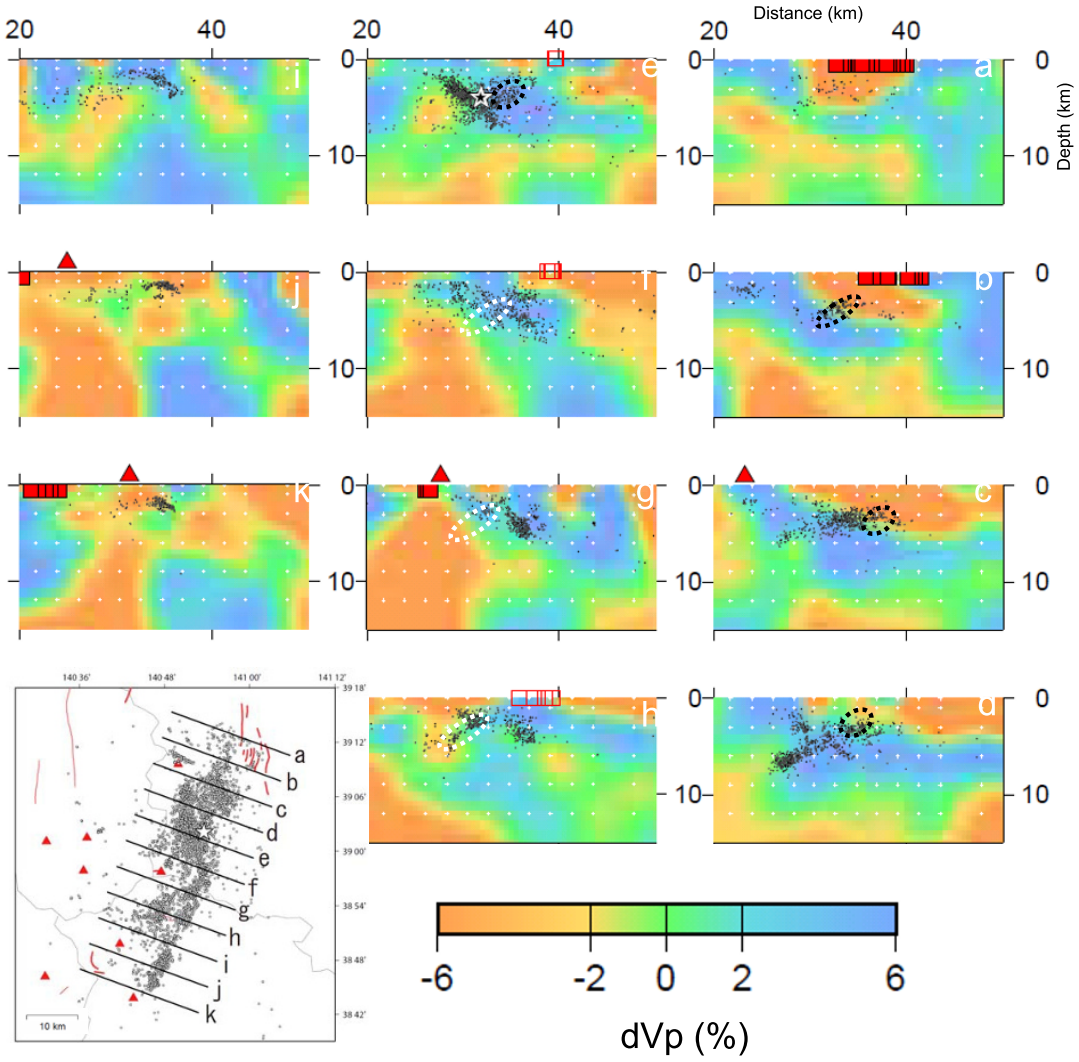

Fig. 10. $V_{p}$ perturbation distribution. Eleven across fault vertical cross sections are shown. Locations of cross sections are shown in the insert map with the label of a to k. Red solid and open squares denote the location of the active fault and the surface deformation, respectively. Triangles denote volcanoes. Circles by broken lines (in $\mathrm{f}, \mathrm{g}$, and $\mathrm{h}$ ) show the high velocity areas along the fault plane where the large coseismic slip occurred (cf. Ohta et al., 2008). White cross denote the grid used in the tomography. Circles by black broken lines (in b, c, d and e) show the areas along the fault plane where the large postseismic slip occurred (cf. Iinuma et al., 2008). 

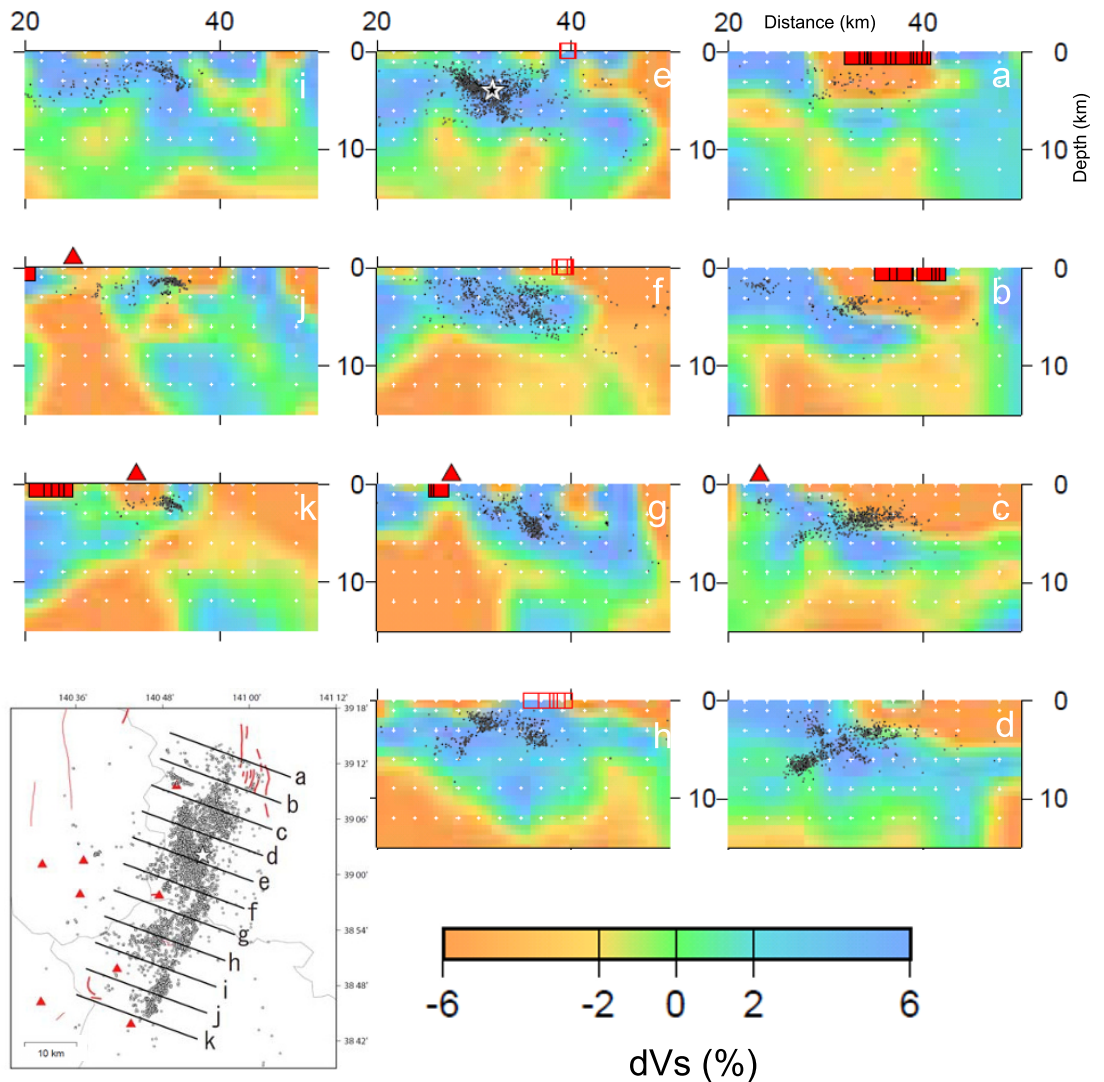

Fig. 11. $V_{s}$ perturbation distribution. Eleven across fault vertical cross sections are shown. Locations of cross sections are shown in the insert map with the label of a to $\mathrm{k}$. Red solid and open squares denote the location of the active fault and the surface deformation, respectively. Triangles denote volcanoes. White cross denote the grid used in the tomography.

(a)

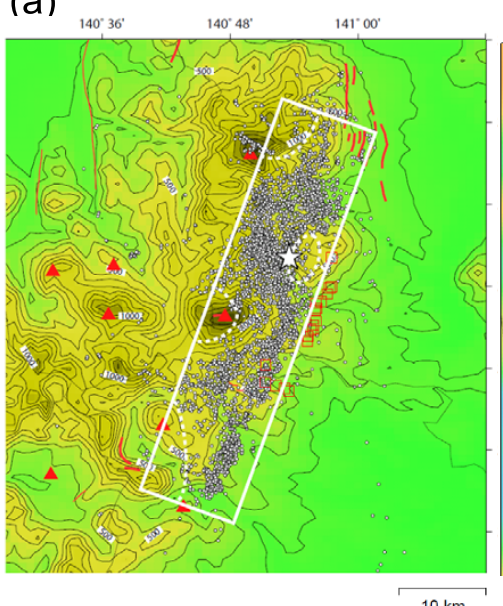

(b)

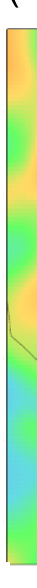

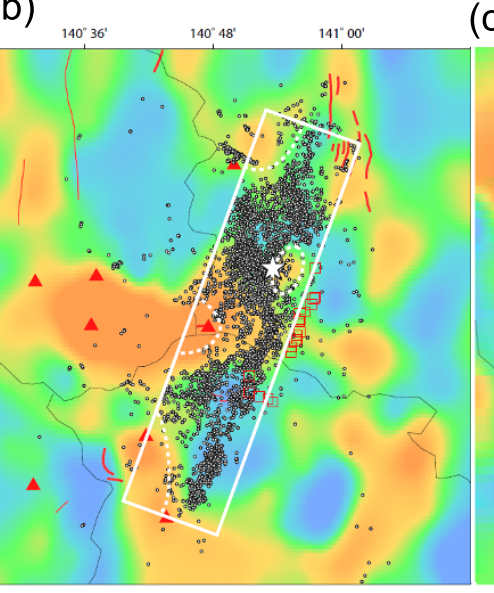

(c) $1400: 3$

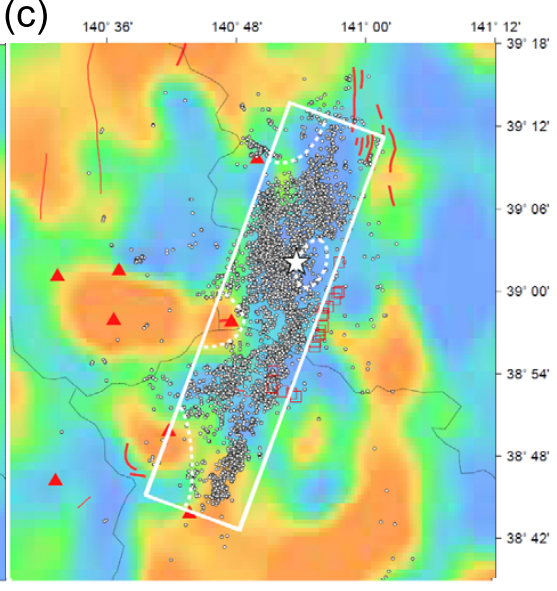

dVs (\%)

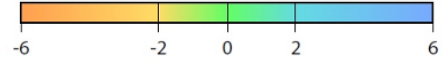

Fig. 12. (a) Topographic map with aftershocks. White rectangular denote the spatial extent of the aftershock area, and the areas with less aftershock are shown by broken lines. (b) $V_{s}$ perturbation at a depth of $9 \mathrm{~km}$ and (c) $6 \mathrm{~km}$.

terpreted as the existence of high-aspect ratio pore with free aqueous fluids (Takei, 2002).

\section{Discussion}

\subsection{Comparison with fault model and coseismic slip}

As discussed above, we relocated hypocenters of the foreshocks, main shock and aftershocks of the 2008 earth- quake. The source fault model and slip distribution for this earthquake is estimated by seismic waveforms and geodetic data (e.g. Asano and Iwata, 2008; Ohta et al., 2008). For example, GPS data indicate that the fault plane is westward dipping and the length of the major slip region is approximately $30 \mathrm{~km}$ (Ohta et al., 2008). According to the detailed slip distribution on the fault plane, the major slip area was 
(a)

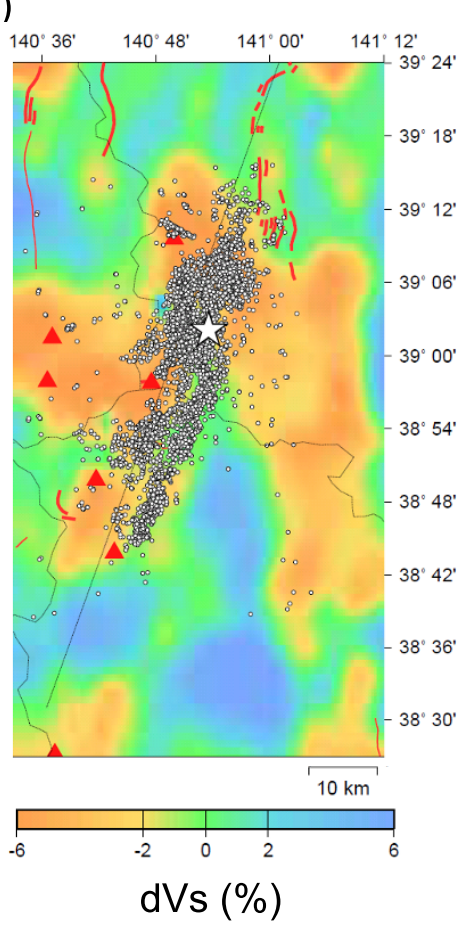

Depth $(\mathrm{km})$

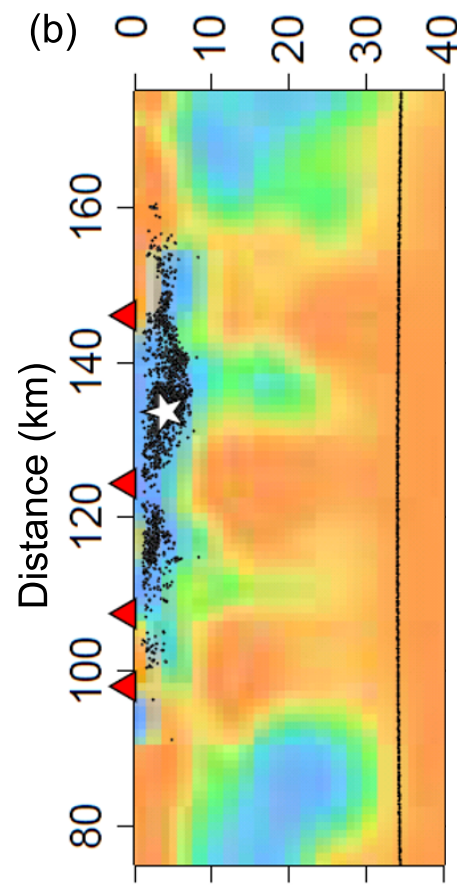

Fig. 13. (a) $V_{s}$ perturbation at a depth of $24 \mathrm{~km}$. Small circles and star denote the aftershocks and mainshock, respectively. Black line denotes the location of cross section. Triangles denote volcanoes. (b) The along-fault vertical cross section. Bold line denotes the location of the Moho discontinuity (Zhao et al., 1990).

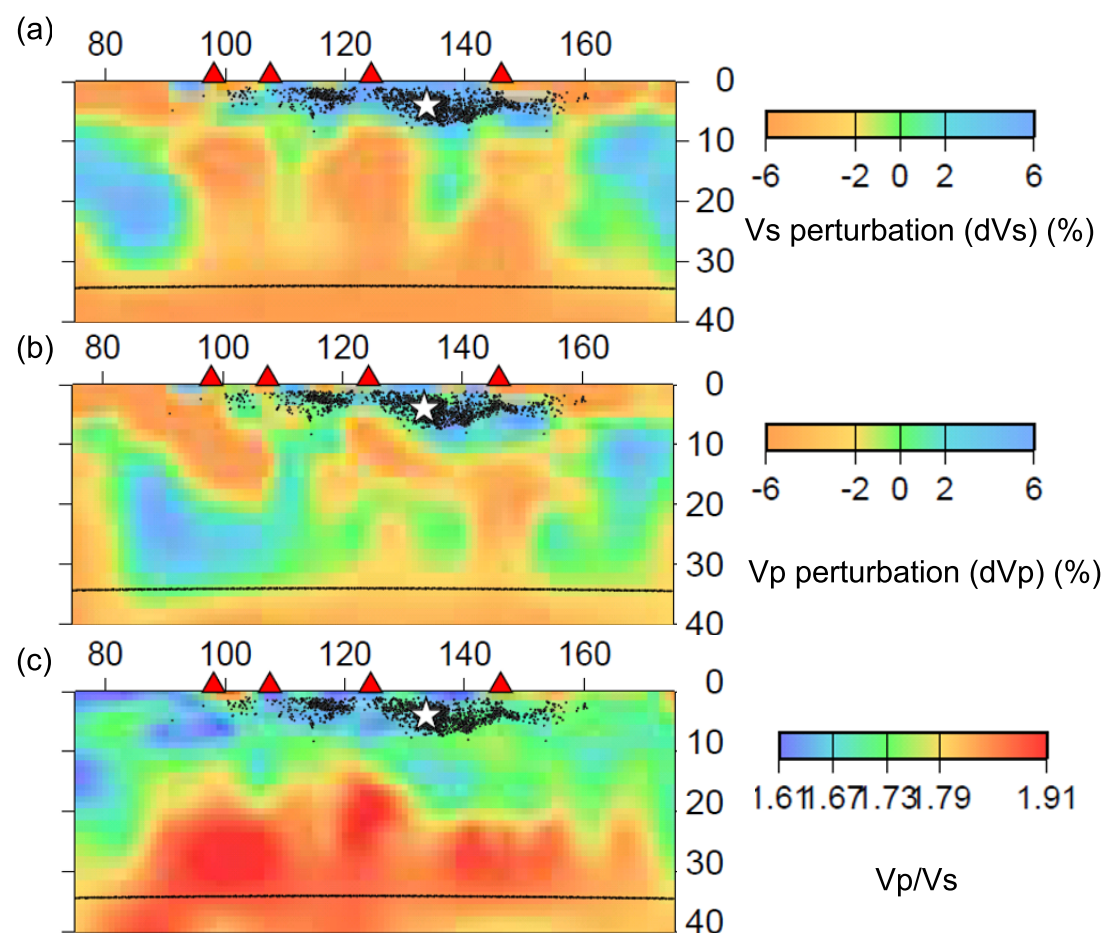

Fig. 14. The along-fault vertical cross section. Bold line denotes the location of the Moho discontinuity. Triangles denote volcanoes. (a) $d V_{s}$, (b) $d V_{p}$ and (c) $V_{p} / V_{s}$.

south of the main shock in a shallow area and the estimated maximum slip is as large as $5 \mathrm{~m}$.

Figure 10 shows the comparison of $V_{p}$ perturbation distribution and location of large coseismic slip. In the central to the southern part $(\mathrm{f}-\mathrm{h})$, the higher velocity region $\left(\delta V_{p} / V_{p}>\sim 0\right)$ extends to the shallower part or the hanging wall side, and the aftershock distribution, the seismic velocity structure, and the relation between them are complex. Large coseismic slip area (shown by circle) has been estimated (Ohta et al., 2008) in this part, and it seems to be 
in the complex and relatively high velocity area. This correspondence between high-velocity body and asperity has observed also in the 2003 northern Miyagi earthquake ( $M$ 6.4) in NE Japan (Okada et al., 2007a), the 2004 Mid Niigata earthquake in central Japan (Okada et al., 2005, 2006), the 1995 southern Hyogo (Kobe) earthquake (M 7.2) (Okada et al., 2007b), the 2005 West off Fukuoka Prefecture earthquake (M 7.3) (Hori et al., 2006) and Park eld, California (Michael and Eberhart-Phillips, 1991; Eberhart-Phillips and Michael, 1993). Such high-velocity area might act as "asperity" which can store large strain and occur large slip (e.g. Hasegawa et al., 2007). In contrast, post-seismic slip areas (Iinuma et al., 2008) are distributed in the shallow low-velocity zone in the northeastern part of the focal area (cross sections $\mathrm{a}-\mathrm{d}$ ). These low velocity area would correspond to the non-asperity areas of a-seismic deformation surrounding the asperity.

\subsection{Relation with volcanoes and deep crustal fluid}

A series of vertical cross-section of the distribution of $S$-wave velocity perturbation in the WNW-ESE direction (across the fault) is shown in Fig. 11. The aftershocks tend to be distributed in the high-velocity region, and the lowvelocity region is distributed just below the hypocenter of the main shock (cross-section e). High electronic conductive region can be detected in this low-velocity region (e.g. Mishina, 2009; Sanakana et al., 2009). This low-velocity region (with moderate to relatively high $V_{p} / V_{s}$, Fig. 11) could be interpreted as the region with high amount of uid (Takei, 2002) and corresponds to crustal uid upwelling.

Note that we can see with the shallow low-velocity and high- $V_{p} / V_{s}$ regions at and around the surface trace of faults. This region can be interpreted as the highly-fractured region includes high amount of uid, which would be originated from deeper part.

Such low-velocity regions beneath the focal area of inland earthquakes in Japan can be commonly seen and interpreted as the region with overpressurized uid, which promote the occurrence of inland earthquake; for example, the 1995 southern Hyogo (M 7.2) (Zhao et al., 1996; Zhao and Negishi, 1998), the 2000 western Tottori (M 7.3) (Zhao et al., 2004), the 1962 northern Miyagi (M 6.2) (Nakajima and Hasegawa, 2003), the 2004 Niigata-Chuetsu (M 6.8) (Okada et al., 2006; Wang and Zhao, 2006) and the 2007 Noto-Hanto (M 7.3) and Niigata-Chuetsu-Oki (M 6.8) (Nakajima and Hasegawa, 2008). This suggests that crustal uid was involved also in the occurrence of the 2008 earthquake. As shown before, the seismic velocity structure also suggests the present earthquake would be a compressional inversion earthquake. The over-pressurized uid imaged as low-velocity zone is the plausible cause of the reactivation of such a compressional inversion fault (Sibson, 1990).

A comparison of the aftershock distribution with the distribution of $S$-wave velocity perturbation at a depth of 6 $\mathrm{km}$ and $9 \mathrm{~km}$ and topographical map is shown in Fig. 12. Low-velocity regions, which might correspond to magma upwelling, are distributed in the vicinity of Mts. Yakeishidake and Kurikoma, and the Onikobe and Narugo volcanoes, all of which are active volcanoes. These results show the low aftershock activity in these regions. This means the low-velocity regions beneath the volcanoes have higher temperature, which make the crustal rocks aseismic.

In this study, we obtained the seismic velocity structure in the whole crust by using the result in the previous study (Okada et al., 2010), in which we have obtained the seismic velocity beneath the focal area of the present earthquake, as an initial velocity model. We compare the seismic velocity structure in the whole crust and the precise aftershock distribution obtained in this study. A vertical cross-section of the distribution of $S$-wave velocity perturbation in the NNESSW direction (along the fault) is shown in Fig. 13. In the lower crust, distinct low-velocity zone exists just beneath the aftershock focal area as shown in the previous study (Okada et al., 2010). The spatial extent of this low velocity zone seems to be almost same as the aftershock focal area. This low velocity zone becomes to be divided in three parts just beneath the volcanoes. The mainshock hypocenter is located just above one of the low-velocity zones. Deep limit of aftershock tend to be shallower where the low-velocity zone exist shallower beneath volcanoes. The aftershocks are distributed within high-velocity areas in the upper crust.

Figure 14 shows the along-fault vertical cross section for $V_{s}$ perturbation $\left(d V_{s}\right)$ (same as Fig. 12(b)), $V_{p}$ perturbation $\left(d V_{p}\right)$ and $V_{p} / V_{s}$. We can see that the low-velocity zone has high $V_{p} / V_{s}$ value in the lower crust, and moderate to low $V_{p} / V_{s}$ value in the upper crust (see also Fig. 11). The high $V_{p} / V_{s}$ value in the lower crust can be interpreted as the area with high amount of melt and the moderate to low $V_{p} / V_{s}$ value in the upper crust can be interpreted as the area of relatively high aspect ratio pore including water (Takei, 2002).

This low-velocity zone in the lower crust would correspond to region of partial melting. High temperature partial melting zone and uid released from it would promote the local crustal deformation and causes stress concentration in the surrounding area to occur the present earthquake.

\section{Conclusions}

Dip of the westward dipping fault plane is estimated to be about 40-50 degrees from aftershock alignment near the mainshock hypocenter. "Eastward dipping" aftershock alignment can be seen in the central part. Low seismic velocity hanging wall for the westward dipping aftershock alignment can be imaged near the mainshock hypocenter. Low velocity zone is imaged beneath the focal area (the hypocenter of mainshock, in particular). Lower limit of aftershock varies spatially and becomes shallower near the volcanoes, where distinct low-velocity areas are distributed in the shallower part. The aftershocks tend not to occur in low-velocity regions, where the temperature would be relatively high. Large coseismic slip areas are also not distributed in low-velocity regions but can be seen in the high velocity areas. The present earthquake is possibly a uiddriven compressional inversion earthquake but strongly inuenced by the recent volcanic activity, thermal structure and complex fault system.

Acknowledgments. We used data from JMA, Hi-net/NIED, National Astronomical Observatory of Japan (Mizusawa) and Tokyo Institute of Technology. We also used data from JNES (Japan Nu- 
clear Energy Safety Organization). We thank Prof. Cliff Thurber and Dr. Haijiang Zhang for providing their programs and valuable discussion. We also thank Prof. R. Sibson for fruitful discussion. We would like to thank the editor, Satoshi Kaneshima and the reviewers for helpful comments. This work was conducted under the support of Grant-in-Aid for Special Purposes, MEXT, Japan.

\section{Appendix A. List of Authors. Listed by University and Institute}

Hiroaki Takahashi, Minoru Kasahara, Takahiro Maeda, Masayoshi Ichiyanagi, Teruhiro Yamaguchi, Masamitsu Takada (Hokkaido University);

Masahiro Kosuga, Katsuhito Sato, Tomohiro Yamada, Kazutoshi Watanabe (Hirosaki Univerisity);

Norihito Umino, Toru Matsuzawa, Satoshi Miura, Tomomi Okada, Yasuo Yabe, Junichi Nakajima, Naoki Uchida, Yusaku Ohta, Yoshihiro Ito, Akira Hasegawa, Takeshi Iinuma, Yukihito Osada, Shuichiro Hori, Toshio Kono, Takashi Nakayama, Satoshi Hirahara, Shuichi Suzuki, Saeko Kita, Hiroaki Tsushima, Mako Ohzono, Aiymjan Mederbekovna Omuralieva, Kouhei Shimamura, Kyohei Nii, Kazuya Toribuchi, Kentaro Emoto, Kota Takatsuka, Erika Hayami, Yoshihiro Yamamoto, Ryota Takagi, Keisuke Yoshida (Tohoku University);

Toshihiko Kanazawa, Takaya Iwasaki, Taku Urabe, Shinichi Sakai, Toshihiro Igarashi, Naoshi Hirata, Takashi Iidaka, Eiji Kurashimo, Aitaro Kato, Yasuhiro Hirata, Izumi Ogino, Shin-ichi Hashimoto, Mamoru Saka, Masato Serizawa, Masaru Kobayashi, Toshio Haneda, Shigeru Watanabe, Kiyoko Tagami, Reiko Miura, Yannis (John) Panayotopoulos (University of Tokyo);

Yoshiko Yamanaka, Haruhisa Nakamichi, Fumihito Yamazaki, Mamoru Yamada (Nagoya University);

Hiroshi Katao, Tsutomu Miura, Tomoya Yamazaki, Masatoshi Miyazawa, Hirooki Fujino, Yoshihisa Iio, Kazuhiro Nishimura, Ken-ichi Tatsumi, Yuuta Kitawaki, Kousuke Yoshikawa (Kyoto University);

Atsuki Kubo (Kochi University);

Takeshi Matsushima, Manami Nakamoto, Yusuke Yamashita (Kyushu University);

Hiroki Miyamachi, Shuichirou Hirano, Sunao Maeno, Chisato Tomari (Kagoshima University);

Youichi Asano, Tetsuya Takeda, Tomotake Ueno, Takayuki Miyoshi, Kazushige Obara (National Institute for Earth Science and Disaster Prevention).

\section{References}

Asano, K. and T. Iwata, Source rupture process of the 2008 Iwate-Miyagi Nairiku earthquake by strong motion data, Programme and abstracts of the 7th General Assembly of Asian Seismological Commisson and the 2008 Fall Meeting of Seismological Society of Japan, A22-07, 18, 2008.

Eberhart-Phillips, D. and A. Michael, Three-dimensional velocity structure, seismicity, and fault structure in the Park eld Region, Central California, J. Geophys. Res., 98, 15737-15758, 1993.

Hasegawa, A., N. Umino, and A. Takagi, Double-planed structure of the deep seismic zone in the northeastern Japan arc, Tectonophysics, 47, 43-58, 1978 .

Hasegawa, A., A. Yamamoto, N. Umino, S. Miura, S. Horiuchi, D. Zhao, and H. Sato, Seismic activity and deformation process of the crust within the overriding plate in the northeastern Japan subduction zone, Tectonophysics, 319, 225-239, 2000.

Hasegawa, A., J. Nakajima, N. Umino, and S. Miura, Deep structure of the northeastern Japan arc and its implications for crustal deformation and shallow seismic activity, Tectonophysics, 403, 59-75, 2005.
Hasegawa, A., N. Uchida, T. Igarashi, T. Matsuzawa, T. Okada, S. Miura, and Y. Suwa, Asperities and quasi-static slip on the sudducting plate boundary east off Tohoku, NE Japan, in The Seismogenic Zone of Subduction Thrust Faults / MARGINS Theoretical and Experimental Earth Science Series, edited by T. H. Dixon and J. C. Moore, Columbia Univ. Press, New York, 2007.

Hori, M., S. Matsumoto, K. Uehira, T. Okada, T. Yamada, and Y. Iio, Three-dimensional seismic velocity structure as determined by doubledifference tomography in and around the focal area of the 2005 West off Fukuoka Prefecture earthquake, Earth Planets Space, 58, 1621-1626, 2006.

Iinuma, T., M. Ohzono, Y. Ohta, and others, Postseismic deformation associated with the Iwate-Miyagi Nairiku earthquake in 2008, Programme and abstracts of the 7th General Assembly of Asian Seismological Commisson and the 2008 Fall Meeting of Seismological Society of Japan, A22-13, 21, 2008.

Japan Meteorological Agency, The Seismological and Volcanological Bulletin of Japan, Japan Meteorological Agency, Tokyo, 2008.

Matsubara, M., N. Hirata, H. Sato, and S. Sakai, Lower crustal uid distribution in the northeastern Japan arc revealed by high resolution 3-D seismic tomography, Tectonophysics, 388, 33-45, 2004.

Michael, A. and D. Eberhart-Phillips, Relations among fault behavior, subsurface geology, and three-dimensional velocity models, Science, 253, 651-654, 1991.

Mishina, M., Distribution of crustal uids in Northeast Japan as inferred from resistivity surveys, Gondowana Res., 16, 563-571, 2009.

Miura, S., T. Sato, K. Tachibana, Y. Satake, and A. Hasegawa, Strain accumulation in and around Ou Backbone Range, northeastern Japan as observed by a dense GPS network, Earth Planets Space, 54, 10711076, 2002.

Nakajima, J. and A. Hasegawa, Tomographic imaging of seismic velocity structure in and around the Onikobe volcanic area, northeastern Japan: Implications for uid distribution, J. Volcanol. Geotherm. Res., 127, 118, 2003.

Nakajima, J. and A. Hasegawa, Existence of low-velocity zones under the source areas of the 2004 Niigara-Chuetsu and 2007 Niigarta-ChuetsuOki earthquakes inferred fromm travel-time tomography, Earth Planets Space, 60, 1127-1130, 2008.

Ohta, Y., M. Ohzono, S. Miura, T. Iinuma, K. Tachibana, K. Takatsuka, K. Miyao, T. Sato, and N. Umino, Coseismic fault model of the 2008 IwateMiyagi Nairiku earthquake deduced by a dense GPS network, Earth Planets Space, 60, 1197-1201, 2008.

Okada, T., N. Umino, and A. Hasegawa, Rupture process of July 26 2003 northern Miyagi earthquake sequence, NE Japan, estimated from double-difference hypocenter locations, Earth Planets Space, 55, 741$750,2003$.

Okada, T., N. Umino, T. Matsuzawa, J. Nakajima, N. Uchida, T. Nakayama, S. Hirahara, T. Sato, S. Hori, T. Kono, Y. Yabe, K. Ariyoshi, S. Gamage, J. Shimizu, J. Suganomata, S. Kita, S. Yui, M. Arao, S. Hondo, T. Mizukami, H. Tsushima, T. Yaginuma, A. Hasegawa, Y. Asano, H. Zhang, and C. Thurber, Aftershock distribution and 3D seismic velocity structure in and around the focal area of the $2004 \mathrm{mid}$ Niigata prefecture earthquake obtained by applying double-difference tomography to dense temporary seismic network data, Earth Planets Space, 57, 435-440, 2005.

Okada, T., T. Yaginuma, N. Umino, T. Matsuzawa, A. Hasegawa, H. Zhang, and C. Thurber, Detailed imaging of the fault planes of the 2004 Niigata-Chuetsu, central Japan, earthquake sequence by doubledifference tomography, Earth Planet. Sci. Lett., 244, 32-43, 2006.

Okada, T., A. Hasegawa, J. Suganomata, N. Umino, H. Zhang, and C. Thurber, Imaging the heterogeneous source area of the 2003 M6.4 northern Miyagi earthquake, NE Japan, by double-difference tomography, Tectonophysics, 430, 57-81, 2007a.

Okada, T., A. Hasegawa, J. Suganomata, D. Zhao, H. Zhang, and C. Thurber, Imaging the source area of the 1995 southern Hyogo (Kobe) earthquake (M7.3) using double-difference tomography, Earth Planet. Sci. Lett., 253, 143-150, 2007 b.

Okada, T., N. Umino, and A. Hasegawa, Deep structure of the Ou mountain range strain concentration zone and the focal area of the 2008 Iwate-Miyagi Nairiku earthquake, NE Japan-Seismogenesis related with magma and crustal uid, Earth Planets Space, 62, 347-352, 2010.

Sanakana, S., H. Ichihara, M. Mishina, T. Nishitani, M. Uyeshima, T. Mogi, Y. Ogawa, Y. Yamaya, and K. Amita, Resistivity structure around the focal area of the Iwate-Miyagi Inland Earthquake 2008, Programme and abstracts of Japan Geoscience Union Meeting 2009, E112-E005, 2009. 
Sato, H., T. Imaizumi, T. Yoshida, H. Ito, and A. Hasegawa, Tectonic evolution and deep to shallow geometry of Nagamachi-Rifu Active Fault System, NE Japan, Earth Planets Space, 54, 1039-1043, 2002.

Sato, H., S. Abe, N. Kato, T. Imaizumi, T. Ishiyama, S. Koshiya, T. Iwasaki, N. Hirata, H. Saito, and T. Kawanaka, Geologic structure of the source area of 2008 Iwate-Miyagi Nairiku earthquake: Insight from seismic pro ling, Programme and abstracts of the 7th General Assembly of Asian Seismological Commisson and the 2008 Fall Meeting of Seismological Society of Japan, A22-08, 18, 2008.

Shibutani, T., S. Nakao, R. Nishida, F. Takeuchi, K. Wanatabe, and Y. Umeda, Swarm-like seismic activity in 1989, 1990 and 1997 preceding the 2000 Western Tottori Earthquake, Earth Planets Space, 54, 831$845,2002$.

Sibson, R. H., Rupture nucleation on unfavorably oriented faults, Bull. Seismol. Soc. Am., 80, 1580-1604, 1990.

Sibson, R., Rupturing in overpressured crust during compressional inversion-the case from NE Japan, Tectonophysics, 473, 404-416, 2009.

Takada, Y., T. Kobayashi, M. Furuya, and M. Murakami, Coseismic displacement due to the 2008 Iwate-Miyagi Nairiku Earthquake detected by ALOS/PALSAR: Preliminary results, Earth Planets Space, 61, e9e12, 2009.

Takei, Y., Effect of pore geometry on $V p / V s$ : From equilibrium geometry to crack, J. Geophys. Res., 107, doi:10.1029/2001JB000522, 2002.

Toda, S., T. Maruyama, M. Yoshimi, Y. Awata, H. Kaneda, T. Yoshioka, and R. Ando, Surface rupture associated with the Mw6.9 June 2008 Iwate-Miyagi Nairiku, Japan, earthquake, Programme and abstracts of the 7th General Assembly of Asian Seismological Commisson and the 2008 Fall Meeting of Seismological Society of Japan, A22-09, 19, 2008.
Umino, N., T. Okada, J. Nakajima, S. Hori, T. Kono, T. Nakayama, N. Uchida, J. Shimizu, J. Suganomata, S. Gamage, A. Hasegawa, and Y. Asano, Hypocenter and focal mechanism distributions of aftershocks of July 262003 M6.4 northern Miyagi, NE Japan, earthquake revealed by temporary seismic observation, Earth Planets Space, 55, 719-730, 2003.

Wang, Z. and D. Zhao, Seismic images of the source area of the 2004 Mid-Niigata prefecture earthquake in Northeast Japan, Earth Planet Sci. Lett., 244, 16-31, 2006.

Zhang, H. and C. Thurber, Double-Difference Tomography: the method and its application to the Hayward Fault, California, Bull. Seismol. Soc. Am., 93, 1875-1889, 2003.

Zhao, D. and H. Negishi, The 1995 Kobe earthquake: Seismic image of the source zone and its implications for the rupture nucleation, J. Geophys. Res., 103, 9967-9986, 1998.

Zhao, D., S. Horiuchi, and A. Hasegawa, 3-D seismic wave velocity structure of the crust in the northeastern Japan arc, Tectonophysics, 181, 135149, 1990.

Zhao, D., H. Kanamori, H. Negishi, and D. Wiens, Tomography of the source area of the 1995 Kobe earthquake: Evidence for uids at the hypocenter?, Science, 274, 1891-1894, 1996.

Zhao, D., H. Tani, and O. P. Mishra, Crustal heterogeneity in the 2000 western Tottori earthquake region: Effect of uids from slab dehydration, Phys. Earth. Planet. Inter., 145, 161-177, 2004.

T. Okada (e-mail: okada@aob.gp.tohoku.ac.jp), N. Umino, A. Hasegawa, and Group for the aftershock observations of the Iwate-Miyagi Nairiku Earthquake in 2008 